\title{
The Role of GIS for Sustainable Development in Health Sector in Egypt A Case study: Distribution of Public Health Centers in Cairo, Egypt
}

\author{
Christina Albert Rayed \\ Sadat Academy for Management Science \\ Computer and Information System Department \\ Cairo, Egypt \\ Christinalbert2004@yahoo.com
}

\begin{abstract}
The efficient management of big cities requires the knowledge and the integration of the several data necessary to describe the huge number of variables that govern the urban environment evolution. In developing countries, where the resources are scarce or in-homogeneously distributed, the problem of acquiring reliable data is amplified by the local conditions and the integration of data of different nature can be extremely complicated without appropriate instruments.

In the 21st century, almost all public organizations have started to use Information Technologies in Egypt, and the municipalities have been utilized technological. The increasing demands in urban planning and management sectors call for GIS for sustainable development of urban areas. Geographical Information System (GIS) is used as a tool in the World especially developing countries in order to get right decisions and arrange the urban facilities.
\end{abstract}

In the past, information systems for health sector were designed for use centrally with little or no feedback to the source of information and with no impact on local activities. The information systems are a vital element for strengthening the national and local capacities for assessing the situations, for selecting appropriate control measures, and for adapting activities to changes in the situation developments as a tool for their services. Modern tools like remote sensing and Geographical Information Systems (GIS) have now come in handy to address the issues in support data collection, storage, distribution as well as the public participation processes for health sector

In this paper, we present a case study for using GIS as tools in the redistribution of public health centers in some crowed areas in Cairo Egypt taking in account the distribution of population in these crowed areas. In order to sustainable development in health sector in Egypt and public centers and redesign these public centers.

\section{Introduction}

The use of Geographical Information Systems (GIS), facilitates easier, quicker solutions for technically compli- cated, time- absorbing geographical problems (Teefelen et al, 1992, p.11). GIS are powerful computer tools that are used for storing, retrieving, transforming and displaying spatial data for many kinds. GIS are rapidly becoming a key technology for the automated capture, management, analysis and presentation of location- referred data all over the world (Ottens, 1992, p.27).

This ability to store and retrieve data about special aspects of the earth and the way people live on it and the potential to use these data in models of environmental and socioeconomic process in order to learn more about the possible outcomes of natural trends, planning decisions or disaster is not only very important for industrialized countries but also for the developing world (Burrough, 1992, p.17).

There are many actual and potential applications for GIS in developing countries ranging from resource inventory and monitoring through land use planning, land evaluation, biological control and health studies, irrigation and drainage, social and economic planning, disaster avoidance, management of conservation areas and parks to tourism (Burrough, 1992, p.21).

\section{The role of GIS for sustainable devel- opment}

GIS are now being used in far-ranging fields including environmental design, land use planning, resource management, natural hazard mapping, urban and rural asset management, coordinating emergency services and implementing environmental planning for sustainable development. 
That successful application of GIS in resource-poor regions in developing countries will lead to more sustainable development. However, data limitations, the lack of a GIS "presence" in these regions, and technical and human resources barriers to successful GIS implementation will likely continue to impede progress towards full utilization of spatial information technology at local scales for some time to come. Achieving consensus among stakeholders in the community remains a major challenge to GIS applications for sustainable development. GIS technology is increasingly playing a facilitating role for improved decision-making.

The greatest challenge for sustainable development in the less developed world is to bring the scientific advances of the information technology and geographic information revolutions to bear on problems of severe environmental degradation while at the same time improving livelihoods.

Sustainable development has been defined as the process of balancing the need of humans for economic and social development with the need to protect the natural and built environment so that these needs can be met not only in the present, but in the indefinite future" (http://en.wikipedia.org, 2007). According to this definition, sustainable development policies encompass three general policy areas: economic, environmental and social. The relation between among has been shown in Figure1.

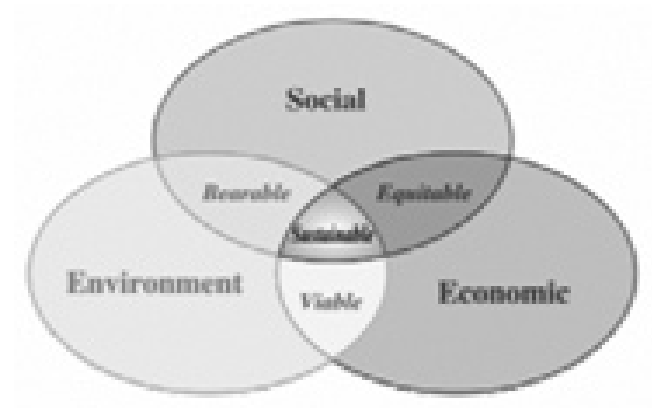

Source: http://en.wikipedia.org, 2007

On the other hand, urban information system provides various information on urban (facilities, urban planning, environment, disaster prevention, water supply, transportation, etc.) for governances to perform effective ad- ministration and decision-making. In order to establish security system for municipal and local governments, effective management of infrastructure should be preceded and the maintenance of the facilities by urban information system is very effective. Maps, statistics, and all the data that can be components of urban information system are produced and managed by each department (transportation, urban planning, water supply and drainage, environmental protection, etc.) Introduction of urban information system can integrate all the information related to each other and make the use of information easier and more efficient.

\section{The role of GIS for sustainable de- velopment in Egypt}

Geographic Information Systems (GIS) as a technology that could be used by Egypt, and by other countries, to assist with natural resource management initiatives and enable increased public participation in decisionmaking.

In Egypt, many of the technical requirements for successful GIS-based development programs already exist, and the incentives to use these tools, especially in the areas of water management, natural resource preservation and public participation, are very strong. Egypt's major challenges in the successful use of GIS for meeting its sustainable development (SD) goals are twofold: first, Egypt has to build the capacity of its citizens, governments, communities and the private sector to use GIS tools; and second, it must increase access to the technologies required.

GIS technology can help in identifying gaps and disparities in service provision, and in drawing communities into the planning process. By helping create a sense of ownership, consensus, acknowledgment and transparency in the district level decision-making process, GIS can be the vehicle for creating a community's development potential.

The special importance of health for Egypt makes it a good example of an area where GIS could be used to advance the country's sustainable development goals. For instance, GIS can be used in decision support sys- 
tems to help disease control and encourage cultural heritage conservation among communities at all levels in Egypt. GIS can also be employed to increase public participation in decision-making. For Egypt, participatory GIS present an opportunity to increase monitoring of water resources and fisheries by local communities. The Egyptian government has designed a number of useful GIS-based applications in different sectors throughout the country; however, the use of GIS is still limited and GIS remains, largely, a technology restricted to the public sector and academia, unknown to the majority of the public. At present, no dedicated department or unit for GIS exists in any ministry or branch of government, save for a few experts and employees who are working under the umbrella of specific projects adopted by the government. Nonetheless, it is important to recognize that the Egyptian government has drawn on GIS technology in a number of promising projects, including the following examples:

MCIT's GIS effort

Ministry of Communication and Information Technology (MCIT) has set up a geographical information system (GIS) workgroup to develop plans and coordinate efforts with the Egyptian GIS community to introduce GIS projects in various business sectors, such as telecommunications, the postal system and others.

The Educational Buildings Project

Ministry of Education initiated a project to develop GIS that would provide information on the status of educational buildings. The system today includes 360,000 photographs and more than four million registers including details about educational buildings and suppliers.

\section{The CAPMAS GIS}

The Central Agency for Public Mobilization and Statistics (CAPMAS) developed a system that covers governorates through a computer network. It enables the governorates to more easily engage in various planning and monitoring operations. The program provides maps for collecting census data and conducting surveys; establishes a territorial GIS for governorates; and provides training on both geographical information and communications systems.

Egyptian Italian Environmental Cooperation Program (EIECP)

Led in partnership with the United Nations Development Programme (Egypt), this project aims to strengthen the capacity of national and local institutions and organizations to effectively manage water resources through a fully tested decision support system (DSS).

The MELMARINA Project: Making management tools for aquatic resources in North Africa

The overall objective of the project is the development of a lagoon ecosystem monitoring mechanism, which combines field surveys, long-term monitoring through field instrumentation and remote sensing with hydraulic/ecological modeling.

\section{Problems of the use of GIS in devel- oping countries}

As most needs for GIS in developing countries are the same as in developed countries, there are some problems to fulfill these needs. The major constraints are probably the cost and the education constraints, but infrastructure and data constraints make the application of a GIS a very time consuming process. It takes a great deal of time, even in industrialized countries, to introduce and to consolidate new ways of working.

1. Cost constraints:

We have to pay extra attention at the financial situations of developing countries, since they do not allow expensive projects to be carried out. GIS Tools are mostly programs, which are developed and sold by developed countries. As currency, exchange rates for developing countries are mostly very bad, these products are often very expensive.

The selection of the appropriate hard and software for a GIS is a delicate matter. In the initial state, it is often difficult to assess the exact functionalities required for the GIS to be used. In order to avoid unnecessary investments it would be unwise to tie the project to a 
completely determined GIS environment. Starting with a very basic system is usually the cheapest and most efficient way. (Teefelen et al, 1992, p.103).

\subsection{Software:}

The most important thing to find out which software to use, is to find out which tools are needed. The appropriate technology should be low in capital costs and utilize as many local resources as possible and can be maintained without a high level of expertise (Burrough, 1992, p.23). ESRI for example offers its Version Arc View 8.2 at a Price of $\$ 1500$ (http://gisstore.esri.com, 2002), but for many purposes the Arc View 3.1 Version is enough which ESRI offers at an educational discount price of $\$ 250$ (Davies, http://www01.giscafe.com/technical_papers/Papers/paper019/GISproj.php, 2002), which is reasonable also for poorer countries. In addition, the range of applications should only include the ones that are efficient and entail low risk. Examples of such applications are automated mapping, cadastral systems, natural resource management and location planning of public services (Ottens, 1992, p.33).

\subsection{Hardware:}

In addition, the hardware is a very cost intensive factor, but basic GIS can also be handled with older Hardware. A case study in Uruguay proved for example that it is also possible to establish a full GIS with 486/66 PCs (http://www01.giscafe.com/technical/papers/Papers/paper019/GISproj.php,2002). The goal for developing countries should be to establish a basic system as soon as possible and not to try competing with the most modern systems. The purchase of hardware and software encompasses only a small part of the financial cost, but it is also the one that is most likely to control (Teefelen et al, 1992, p. 105). Another big factor is the cost of the workforce. Also, skilled labor is rare and because of that, the wages for such workers are quite high. Unfortunately, this is a factor, which cannot be changed easily. In addition, housing and infrastructure often require big investment but for the protection of the sensitive and expensive hardware, saving too much at this point can be dangerous.

\section{Infrastructure constraints:}

All electronic systems require stable power supplies and good air conditioned housing free of damp and bugs (Burrough, 1992, p.23). Many developing countries cover huge areas of land yet the people may be concentrated in a few small areas around large cities. To cover the whole country at a reasonable scale is not only very time consuming and expensive (Burrough, 1992, p.24); it is also a problem that many areas are very hard to access and to find appropriate conditions for data collection in such regions can sometimes be almost impossible. In addition, many of those areas are too far away from commercial support services. When problems occur with the hard- or software, the companies are mostly too far away to give appropriate support.

\section{Educational constraints:}

In developing countries, there is still a high level of illiteracy and only a few of them know how to work with computers. Although the number of computer training institutes is rapidly increasing, the number of people that have mastered computer skills is very low. The way in which this problem is dealt with varies. In quite a large number of GIS projects local staff is selected and sent abroad to attend GIS courses. In other projects, the training is conducted "on the spot" (Teefelen p. 107).

Both methods have the problem that they are very expensive, because it is either to import skilled people, which need to be paid much higher wages or pay the seminar-developed countries. As internet facilities become more and more available also for countries, there is a third way to solve this problem: online seminars. It is only in the new computer based instructional products have appeared.

Companies like ESRI offer many basic modules free and further education (http://campus.esri.com, 2002). On 7 June 2002, Campus membership was 144,000 members from 180 countries (Ospina, 2002, p.4).

\section{Data Constraint}

Very often an effective implication is hampered by the 
limited availability of useful data. There are two aspects to this problem. The first is the pure existence of data; the second is the accessibility of existing data (Teefelen et al, 1992, p.105)

\subsection{Existence of data:}

Making maps as well as updating them is a costly and time- consuming activity, therefore detailed and current maps are scarce (Teefelen et al, 1992, p.105). Often many field surveys have to be done to cover the whole area with at least a detailed topographical map. In addition, information about natural resources, soils and vegetation, climate and geology are often not available. In this case, it is important to know which are the most important information influencing decisions in the country.

Moreover, socioeconomic phenomena like population density, growth, and movement tent to be much more variable and harder to predict than in developed countries. This means that also the maintenance of a GIS might involve more work. In addition, many of those countries are or were not democratically ruled. This means that especially information about the economy, literacy and poverty might be faked, so data has to be scrutinized if there is any possibility that data is not trustworthy.

\subsection{Accessibility of data}

In many countries that are ruled by a military dictatorship, good information is available, but not commonly, because they have been considered military secrets. Satellite imagery seems to help in this case, but as those countries mostly do not have their own satellites, remote sensing data can only be purchased from developed countries. This does not only increase the dependency once more it is also a problem because the latest imagery is often not available for public use. Even if it is, you have to decide to purchase either cheap and old or new but expensive data. As data is the most important thing about a GIS, it has to be paid attention that the cost for things like soft and hardware and the availability of data stand in an appropriate relation (Teefelen et al, 1992, p.105).

\section{Political stability:}

The idea of building a database of a country's resources and of using that information to help plan and direct the future development of the country concerned is only possible within the context of collective commitment and political stability" (Burrough, 1992, p.24). Not only the financing of a project over a long period is very difficult; it is also hard to predict, how stable the political system of the country and its neighbors will be. As the installation of a fully functioning GIS takes a lot of time, there is a risk, that the project cannot be accomplished.

\section{Case study: Distribution of public health centers in Cairo Egypt}

The organizational structure of the Ministry of health consists of two functional structures: the administrative structure and the service delivery structure. The government sector responsible for health includes the Ministry of Health, the Ministry of Education that is responsible for University Hospitals, other ministries and the public organizations responsible for teaching, hospitals and institutions.

The public sector includes the public organization for health insurance (HIO), the Curative Care Organization (CCO) and other public sector organizations that provide mainly hospital services. The private sector provides its services through private clinics, polyclinics or group practices managed by private physicians, nongovernmental organizations (NGOs) and private hospitals.

Ministry of Health includes the administrative structure and the service delivery structure. There is a formal referral system in the Ministry of Health system. Today, most Egyptians have reasonable access to free primary health care provided by a government team of health personnel. The system operates through a vast network of more than 2209 rural and 238 urban health units, 161 integrated hospitals, 337 women health centres, 164 maternal and child health centres, 354 health offices, 214 district general hospitals, 196 specialized hospitals, fever hospitals and 13 teaching hospitals and 
institutes. However, the government's success in bringing modern primary health care within reach of most communities has not been matched by a similar success in increasing cultural acceptability. The administrative organization of the Ministry of Health comprises the central headquarters and the governorate-level health directorates. The main functions of the central headquarters include planning, supervision, and program management. The population portfolio, which was previously an independent Ministry, was merged into the Ministry of health in 1995. All functions of the central headquarters are divided into five broad sector divisions: 1) central administration for the minister's office, 2) curative health services, 3) population and family planning, 4) basic and preventive health services, and 5) administration and finance.

In order to fulfil its responsibilities and achieve public health goals, MOHP has developed a health sector reform programme which aims to build on the strengths of the current health system and rectify the weaknesses. The health sector reform programme is based on the following guiding principles:

-Universality: The system aims to cover the entire population with the provision of a basic package of priority services. Every person in the country will have the same access to and benefits from basic health services.

-Quality: The standards of health services and facilities will be improved and assured, and diagnostic, clinical and nursing education and training will be enhanced. Professional and ethical treatment, and public satisfaction and trust should characterize the health care system.

-Equity: Financing for health services should be based on ability to pay, while the provision of services should be based on need. All regions of the country and people of all income levels will have a fair share in the health system.
-Efficiency: Allocation and mobilization of human, financial and infrastructure resources for health services will be based on population needs and cost-effectiveness. The government and citizens will obtain the best health value for the money. -Sustainability: The continuity, self-sufficiency and lasting establishment of the health services will be ensured, as will be the services for the health and well-being of future generations.

In this paper, we select Miser El-Kadema area in Cairo. In this selected area, there are only one public hospital and four public centers as seen in figure 2:

- Dar El-Salam hospital

- Al-Zahraa Center

- Amer mosque center

- Abo El-Sawad center

- Ain Al-Sera center

Dar Al-Salam hospital has all clinics but in the other four public centers there are dental clinics, pediatric clinics, and obstetric \& gynecology clinics.

Miser El-Kadema area is a very crowded area in Cairo With a high population. But, we can see that the pubic health services is not sufficient for this high population in this area specially for the other clinics that is found only in Dar EI-Salam hospital.

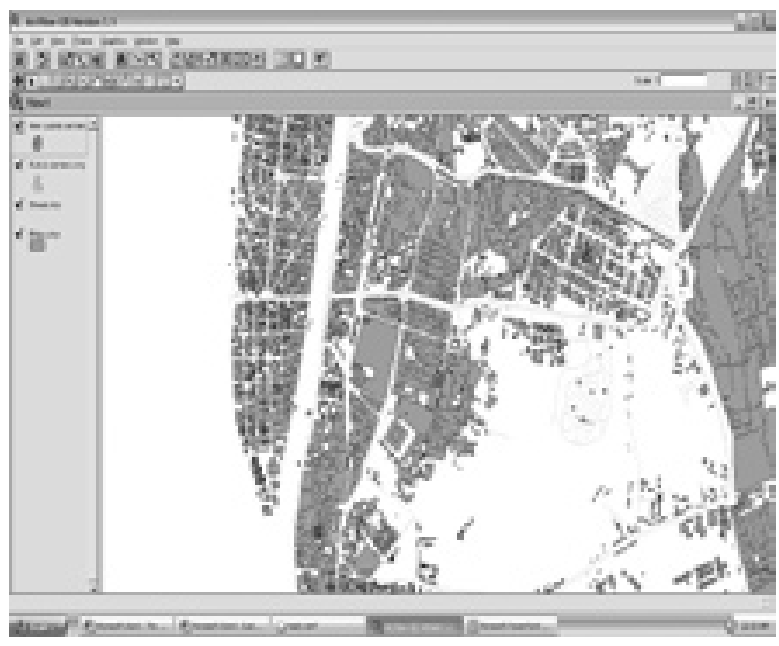


in the previous public centers. In addition to increase the number of the pubic centers in this area. As seen in figure 3 we can increase anther two public centers

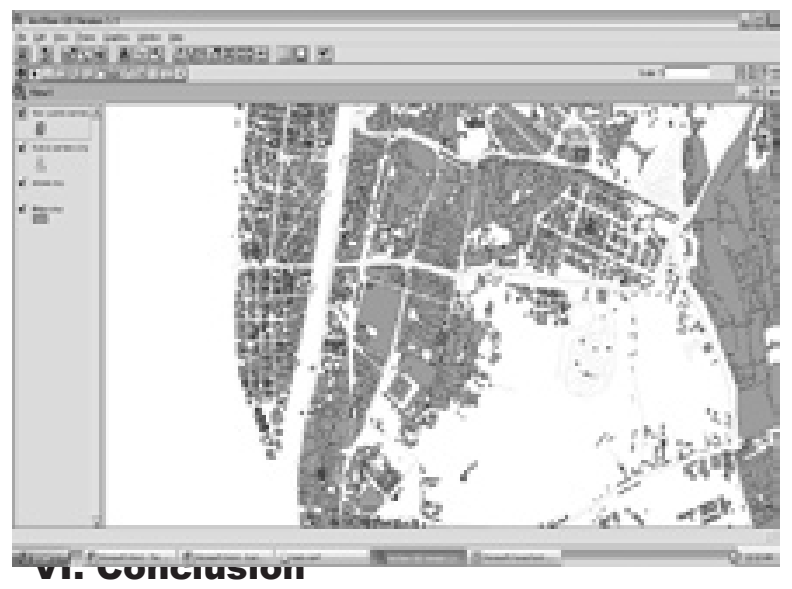

GIS is a relatively recent and complex technology, which explains why it has not been used to its full potential, especially in the health domain where it is extremely promising.

Hardware and software development has produced systems with functions and interfaces, which make them easier to use. It should be noted that GIS is not a tool designed to increase the quality of data. It is paramount to review all the steps in the information flow to guarantee quality and adequacy. Otherwise, the powerful tools of GIS can easily lead to misinformation and misinterpretation, particularly by someone unfamiliar with its use. Ecological fallacies, problems of scales, and propagation of error are frequent, and should be given serious consideration. In addition, GIS is not a magical solution to all the difficulties regarding information in health care, but is a powerful tool capable of transforming the way with which information is dealt with.

Using GIS in developing countries is something that seems very unusual for many people, and the number of constraints show, that it is still a problem. However, nowadays there are a big number of GIS projects taking place in developing countries. Several standard PC packages have proven to be very useful in western organizations. These packages can also be used in de- veloping countries for prototype purposes (Meijer and Kuipers, 1992, p.45).

Many of the constraints seem very inhibiting in the first instant, but in many cases, there is a way to solve most of them. The important thing about a GIS is that it is not only a nice thing to make countries look more modern, it is a very good investment in the future of a country. GIS can be a cheap and effective way to improve decision-making processes in developing countries, as long as one always keeps the goal in mind: The installment of an appropriate GIS, not the competition with the latest technology.

\section{Acknowledgments}

The author wishes to thank all the personnel and the volunteers for their support.

\section{References}

\section{Books}

1. Burrough, P.A (1992).: Possibilities and constraints of GIS applications in developing countries.

2. Ottens, H.F.L. (1992): The profileration of GIS: How about the developing countries?; Possibilities and constraints of GIS applications in developing countrie.

3. Ospina, M.(2002): Virtual Campus GIS Teaching Resources; Third European GIS Education Seminar EUGISES, Girona, Spain.

4. Teefelen,v.P; Gustavson, V.L.; Verkoren, O. (1992): Epilogue. Dealing with the constraints of GIS Applications in Developing countries.

5. Meijer,E.N., Kuipers,K.W. (1992): GIS: Start at the bottom! The use of low end applications; Possibilities and constraints of GIS applications in developing countries.

\section{Internet}

1. http://en.wikipedia.org, 2007.

2. http://gisstore.esri.com, 2002.

3. http://www01.giscafe.com/technical_papers/Papers/ paper019/GISproj.php, 2002).

4. http://campus.esri.com, 2002. 